\section{Research data access bill issued}

The White House Office of Management and Budget (OMB) has issued the final version of the rules allowing members of the general public access to data from federally funded research. The new rules, mandated by a measure quietly inserted into a Senate appropriations bill last year (Nature Med. 5, 8; 1999) applies to all research funded by the federal government after 8 November 1999. Although the OMB rules seem to address many of the concerns voiced by scientists when the legislation was passed, some observers are fearful that the new regulations will still be abused by special-interest groups.

"OMB has done probably about the best job we could have expected given the way the law was worded. They have made some very constructive steps," Wendy Baldwin, deputy director of extramural research at the National Institutes of Health, told Nature Medicine. The original legislation, apparently inserted into the appropriations bill at the request of industries stung by new environmental protection rules, targets research cited to support new federal regulations.

Under the law, the OMB was required to amend its rules to place such data under the Freedom of Information Act, which would allow any citizen to request copies of the raw data used to support a researcher's conclusions. In its final ruling, the OMB specifically excluded data that could identify individual subjects in clinical research and data from studies that are awaiting publication, two areas that had raised concern among researchers.

Although the rules do narrow the scope of the law marginally, scientists whose research has been cited in federal rule-making in the past are still uneasy. "Under this regulation, there are still a multitude of ways that special interests can exploit the promulgated rules to slow or avoid the use of scientific information that they don't like," claims George Thurston, a professor in the Department of Environmental Medicine at New York University. Thurston says that in the past, companies have tried to bury researchers in lawsuits and information requests, and the new rules will provide additional ammunition for such attacks.

Alan Dove, New York

\title{
Cancer research director steps down after 17 years
}

"1999 will be remembered as the year that Piet Borst stepped down as director of research at The Netherlands Cancer Institute (NCI) after holding this position for 17 years," incoming director Anton Berns told Nature Medicine.

Borst, who left the position at the Dutch mandatory retirement age of 65 , will continue teaching at the University of Amsterdam and researching multi-drug resistance as an honorary staff

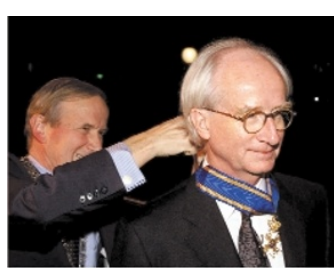

Piet Borst

and running," adds Berns. He says that other new areas of emphasis will include molecular pathology and genetic counseling for inherited cancers, building on the institute's strong database of patient records. Berns will continue to run his own laboratory researching mouse cancer models. Borst, who was given the country's highest honor, Commander in the Order of the Dutch Lion, by the Queen of member at the NCI. He is credited with expanding the institute, which now has around 1,500 employees, into one of the largest cancer research centers in Europe, and for improving the interaction between basic and clinical researchers.

Berns previously served as Head of Molecular Genetics at NCI. He inherits the job on the cusp of a period of massive expansion. With an FYOO budget of $\$ 87$ million, the NCI is planning to build a new hospital and renovate current research facilities. "We are also hoping to get a new micro-array analysis facility up The Netherlands in November, says of Berns that he is "an outstanding scientist and administrator-the institute is in excellent hands." His only concern for the future of the NCI is the weak political status of scientific research in Holland. "Science funding is lagging far behind...other Western countries'," he complains; "Compared to the substantial increases in funding for cancer research in the US, for instance, cancer research in The Netherlands is seriously underfunded."

Kristine Novak, New York

\section{Canada ushers in new era in health research}

Legislation unveiled last month repealing the four-decades-old Medical Research Council (MRC) and establishing a virtual Canadian Institutes for Health Research (CIHR) network will transform Canada's biomedical and healthcare research community if approved by Parliament this 1 April (Nature Med. 4, 989; 1998).

The CIHR will be much larger and complex in scope than the MRC and is now taking shape under the guidance of MRC president Henry Friesen, who has been appointed chair of the interim CIHR governing council. A 22 November discussion paper on the network, now undergoing public scrutiny, envisions 10-15 virtual institutes. Each will "likely focus upon different diseases and fundamental processes, something like the [extramural program of the US National Institutes of Health], and investigators will submit their grant applications to the most relevant institute," explains Peter Wells of the University of Toronto.

The changing biomedical landscape has troubled some. "Since the institutes will have a significant role in facilitating the development of new research fields, as distinct from investigator-initiated research, there is concern that progress in existing fields not represented by an institute may be disadvantaged," says Wells. "It remains to be seen how the support of novel and high-risk approaches rather than diseases or health processes will fare in the CIHR, although the stated intent is to fund all areas equitably."

But many more in the Canadian research community welcome the new era in Canadian research. Francis Vaccarino, co-chair of the Knowledge Management subcommittee of the CIHR interim governing council, insists, "Health research will be more integrative, collaborative, better-coordinated and better-funded."

More than CAN\$500 million (US\$338 million) will drive the CIHR start-up through FY01-02 and the transfer of "health-related research" to the CIHR from Canada's other science agencies, such as the MRC and the Natural Sciences and Engineering Research Council. The funding is not only "more money, but money that's more intelligently spent," claims federal health minister Allan Rock.

Brian Hoyle, Nova Scotia 